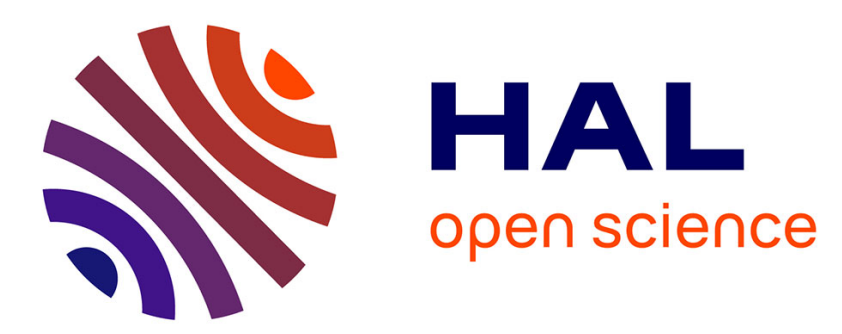

\title{
Decomposition mechanisms of trinitroalkyl compounds : a theoretical study from aliphatic to aromatic nitro compounds
}

\author{
Guillaume Fayet, Patricia Rotureau, Benoît Minisini
}

\section{- To cite this version:}

Guillaume Fayet, Patricia Rotureau, Benoît Minisini. Decomposition mechanisms of trinitroalkyl compounds: a theoretical study from aliphatic to aromatic nitro compounds. Physical Chemistry Chemical Physics, 2014, 16 (14), pp.6614-6622. 10.1039/C3CP54719A . ineris-00961540

HAL Id: ineris-00961540

https://hal-ineris.archives-ouvertes.fr/ineris-00961540

Submitted on 20 Mar 2014

HAL is a multi-disciplinary open access archive for the deposit and dissemination of scientific research documents, whether they are published or not. The documents may come from teaching and research institutions in France or abroad, or from public or private research centers.
L'archive ouverte pluridisciplinaire HAL, est destinée au dépôt et à la diffusion de documents scientifiques de niveau recherche, publiés ou non, émanant des établissements d'enseignement et de recherche français ou étrangers, des laboratoires publics ou privés. 


\title{
Decomposition mechanisms of trinitroalkyl compounds: a theoretical study from aliphatic to aromatic nitro compounds
}

\author{
Guillaume Fayet $^{\mathrm{a}, *}$, Patricia Rotureau ${ }^{\mathrm{a}}$, Benoit Minisini ${ }^{\mathrm{b}}$ \\ a Institut National de l'Environnement Industriel et des Risques (INERIS), Parc Technologique Alata, \\ BP2, 60550 Verneuil-en-Halatte, France \\ ${ }^{\mathrm{b}}$ Institut Supérieur des Matériaux et Mécaniques Avancés du Mans (ISMANS), 44 Av. Bartholdi, \\ 72000 Le Mans, France
}

*Corresponding author: guillaume.fayet@ineris.fr; tel: +33(0)344618126; fax: +33(0)344556565

\section{ABSTRACT}

The chemical mechanisms involved in the decomposition of trinitroethyl compounds were studied for both aliphatic and aromatic derivatives using density functional theory calculations. At first, in the case of 1,1,1-trinitrobutane, used as a reference molecule, two primary channels were highlighted among the five investigated ones: the breaking of $\mathrm{C}-\mathrm{N}$ bond and the HONO elimination.

Then, the influence of various structural parameters was studied for these two reactions by changing the length of the carbon chain, adding substituents or double bonds along the carbon chain. If some slight changes in activation energies were observed for most of these features, no modification of the competition between the two investigated reactions was highlighted and the breaking of the C-N bond remained the favoured mechanism.

At last, the reactions involving the trinitroalkyl fragments were highlighted to be more competitive than reactions involving nitro groups linked to aromatic cycles in two aromatic systems $(4-(1,1,1-$ trinitrobutyl)-nitrobenzene and 2-(1,1,1-trinitrobutyl)-nitrobenzene). This exhibited that aromatic nitro compounds presenting trinitroalkyl derivatives decompose from their alkyl part and may be considered more likely as aliphatic than as aromatic regarding the initiation of their decomposition process.

Keywords: Nitro compounds; Decomposition mechanisms; Density Functional Theory. 


\section{INTRODUCTION}

Nitro compounds are substances recognized as potentially hazardous due to the presence of nitro groups. Besides, some of them are commonly used in high explosive compositions ${ }^{1}$. So, particular attention is needed for the storage, transport and handling of such compounds.

For this reason, knowledge on the hazardous properties of nitro compounds is needed. In recent years, works have also been conducted for the understanding and prediction of physico-chemical hazards based on theoretical approaches ${ }^{2-9}$. Indeed, these computational methods became powerful with the improvement of computer capabilities, allowing access to new information at molecular level.

For instance, quantitative structure property relationship models (QSPR) were developed to predict the hazardous properties of energetic compounds from descriptors of their molecular structures ${ }^{2,3,5}$, ${ }^{10-14}$. In particular, models were developed in a previous work for the prediction of the impact sensitivities of nitro compounds ${ }^{11}$. High predictive powers were obtained for nitramine and nitroaliphatic compounds with $\mathrm{R}^{2}=0.85$ and 0.88 , respectively, as evidenced on external validation sets. However, early efforts to predict impact sensitivities of aromatic compounds reveal fairly poor, achieving $R^{2}$ values of 0.54 only. This failure was proposed to be related to a too large diversity of compounds in the training data set regarding its small size. Indeed, some subgroups of molecules among the aromatic nitro compounds of the data set were identified to present special decomposition features. This was in particular the case for compounds presenting $-\left(\mathrm{CH}_{2}\right)_{n}-\mathrm{C}\left(\mathrm{NO}_{2}\right)_{3}$ aliphatic fragments.

Similar analysis had been already proposed to distinguish between ortho and non ortho substituted nitrobenzene derivative for the prediction of their heats of decomposition ${ }^{15}$. Indeed, as in the case of o-nitrotoluene derivatives ${ }^{16}$, the interaction of nitro groups with the ortho groups can induce a specific decomposition pathway. Besides, a model with high predictive capabilities was achieved by considering only the compounds presenting no substituent in the ortho position to the nitro group that followed the same decomposition process which is the dissociation of the carbon-nitro bond ${ }^{17}$.

So, one purpose of the present study was to identify, in the same way, key features for compounds presenting $-\left(\mathrm{CH}_{2}\right)_{n}-\mathrm{C}\left(\mathrm{NO}_{2}\right)_{3}$ fragments that would have caused troubles in the development of an accurate QSPR model for the impact sensitivity of aromatic nitro compounds ${ }^{11}$. For this reason, the mechanisms involved in the decomposition of compounds presenting $\mathrm{C}\left(\mathrm{NO}_{2}\right)_{3}$ fragments were studied, starting with the aliphatic 1,1,1-trinitrobutane to aromatic compounds presenting $-\left(\mathrm{CH}_{2}\right)_{\mathrm{n}}$ $\mathrm{C}\left(\mathrm{NO}_{2}\right)_{3}$ fragments.

The thermal decomposition of nitro compounds has been studied in numerous experimental ${ }^{18-21}$ and computational studies ${ }^{16,17,22-26}$. Different decomposition paths upon the type of nitro compounds under investigation ${ }^{27}$ were thus suggested, and in particular for nitroalkanes ${ }^{28}$. The main reactions extracted from literature focused on the decomposition of nitroalkanes are presented in Figure 1.

Reaction 1 consists in the homolytic dissociation of the $\mathrm{C}-\mathrm{NO}_{2}$ bond. This reaction is commonly considered as the main reaction path for most of the nitro compounds ${ }^{27}$. It was in particular considered experimentally by Cottrell et al. as the primary mechanism of the thermal decomposition 
of trinitromethane in the range $380-430^{\circ} \mathrm{C}^{29}$. Using theoretical analysis ${ }^{30}$, Kiselev came to the same conclusion. In various works ${ }^{25,31}$, this reaction was even only used to characterize the decomposition of nitroalkanes.

Reaction $\mathbf{2}$ issues from a nitro-nitrite isomerization that was considered in various experimental or theoretical studies ${ }^{18,24,26,30,32}$. It was notably characterized theoretically by Khrapkovskii et al. for a series of nitroaliphatic compounds ${ }^{32}$. Nevertheless, most of these studies considered it as non competitive with reactions 1 and 3 .

Reaction 3 is the HONO elimination. This channel has been considered in various studies of nitroaliphatic compounds ${ }^{33-35}$ notably suggested by pyrolysis experiments on nitropropanes ${ }^{36}$. More recently, Pauler et al. ${ }^{37}$ proved theoretically that this mechanism was favored versus reaction 1 at low temperatures (reaction 1 being favored at higher temperatures $\left(>150^{\circ} \mathrm{C}\right)$ ) for dinitropropyl compounds, with computational results in accordance with experiments.

Reaction 4 is the mechanism by elimination of $O$ that was early proposed by Taylor for the decomposition of nitromethane ${ }^{38}$ without being noticed in later studies. Reaction $\mathbf{5}$ is the breaking of the $\mathrm{C}-\mathrm{C}$ bond. Even if no recent studies highlighted this channel among the main mechanisms involved in the decomposition of nitroalkanes, it represents the typical mechanism involved on the decomposition of alkanes ${ }^{39-41}$.

Focusing on trinitroalkanes, Kisilev ${ }^{30}$ studied the decomposition of trinitomethane using quantum chemical calculations. The $\mathrm{C}-\mathrm{N}$ bond breaking was proposed to be the primary mechanism. However, the reactions 1 and $\mathbf{2}$ were only considered whereas the HONO elimination (reaction 3) was proposed to be critical in the decomposition of trinitroalkanes in the experimental works of Nazin et al. ${ }^{42,43}$. Moreover, no study considered the five reactions $\mathbf{1}$ to $\mathbf{5}$ in a same study.

In the present study, an extended theoretical study was performed, using the density functional theory, to clarify the decomposition mechanisms of trinitroalkyl compounds. Reactions 1-5 were computed for the 1,1,1-trinitobutane, chosen as a reference molecule, and a series of derivatives to evidence the influence of structural features, e.g. presence of substituents in various positions, or the carbon chain length. These reactions were also compared to the mechanisms involved on the nitro groups on the aromatic cycle for nitroaromatic compounds. It allowed to evidence the specific mechanism of decomposition of compounds presenting trinitroalkyl fragments (-R-C(NO$\left.)_{3}\right)_{3}$ among aromatic nitro compounds since they would be more likely considered as nitroaliphatics regarding the initiation of their decomposition process.

\section{COMPUTATIONAL DETAILS}

All calculations were carried out using the density functional theory with the PBEO hybrid functional ${ }^{44}$ as implemented in Gaussian09 software ${ }^{45}$. All structures (reactants, products, local minimum intermediates and transition states) were optimized using the $6-31+G(d, p)$ basis set. The nature of stationary points was checked on harmonic frequencies computed at same level of calculation. The spin-unrestricted formalism was employed for the calculations on open shell molecules and spin contamination appeared to be negligible for all computed radical species (with $\mathrm{S}^{2}$ values close to 0.75). 
The PBE0/6-31+G(d,p) level of theory was already successfully used for nitro systems ${ }^{16,17}$. Good agreement was highlighted in table S1 for the calculation of the bond dissociation energies of three $\mathrm{C}\left(\mathrm{NO}_{2}\right)_{3}$ compounds with experimental data. Moreover, table S1 (in Supporting Information) exhibited the accuracy of this method for the trinitromethane (see in Figure 2) on a geometrical point of view when compared to experimental data ${ }^{46,47}$ and results obtained with larger basis set ${ }^{48}$.

In this study, all energetic values were considered in terms of Gibbs Free Energies $(\Delta G)$ since entropic contributions were of importance as already demonstrated for nitroaromatic compounds on similar reactions in previous works ${ }^{16,17}$. This $\Delta G$ values were issued from harmonic frequencies using the standard statistical approaches, as implemented in Gaussian09 software.

To quantify the effect of the substituent groups on the different energetic values, different global reactivity descriptors were evaluated, e.g. the chemical hardness $(\eta)^{49}$, the electronegativity $(\chi)^{50}$ and the electrophilicity index $(\omega)^{51}$.

$$
\begin{aligned}
& \chi=(I+A) / 2 \\
& \eta=(I-A) / 2 \\
& \omega=\chi^{2} / 2 \eta
\end{aligned}
$$

where $\mathrm{I}$ and $\mathrm{A}$ are the potential ionization and the electron affinity of the molecules. A second approximation was finally used since the opposite of HOMO ( $\left.\varepsilon_{\text {HOMO }}\right)$ and LUMO ( $\varepsilon_{\text {LUMO }}$ ) energies were used to evaluate the vertical potential ionization, $I \approx-\varepsilon_{\text {HOMO }}$, and vertical electron affinity, $A \approx-\varepsilon_{L U M O}$; respectively.

\section{RESULTS AND DISCUSSION}

\section{Decomposition of the 1,1,1-trinitrobutane}

The five decomposition mechanisms identified in Figure 1 were computed for the 1,1,1trinitrobutane (TNBt), as a reference molecule. Table 2 and Figure 3 summarize the energetic profiles obtained for these mechanisms. All calculated molecular structures (reactive, products, transition states and local minima) are represented in Figure 4.

The first mechanism consisted in the direct breaking of the carbon-nitrogen bond related to nitro groups. For the 1,1,1-trinitrobutane (S0), such dissociation was involved for two positions, $\mathbf{a}$ and $\mathbf{b}$, as represented in Figure 1. However, the loss of both nitro groups led to the same radical (denoted Rad1) with a computed dissociation energy $\Delta \mathrm{G}_{\text {diss }}=21.3 \mathrm{kcal} / \mathrm{mol}$. So, the breaking of the $\mathrm{C}-\mathrm{NO}_{2}$ bond appeared to be strongly energetically lower than for nitro groups linked to benzene rings (e.g. $\Delta G_{\text {diss }}=58.2 \mathrm{kcal} / \mathrm{mol}$ for nitrobenzene ${ }^{17}$ and $55.1 \mathrm{kcal} / \mathrm{mol}$ for o-nitrotoluene ${ }^{16}$ ).

The second mechanism was initiated by isomerisation of the 1,1,1-trinitrobutane (SO) to a local minimum (LM1), corresponding to a nitrite form, via the transition state TS1. Then, the breaking of the O-NO bond in the nitrite fragment led to the formation of two radicals: $\mathrm{CH}_{3}-\left(\mathrm{CH}_{2}\right)_{2}-\mathrm{C}\left(\mathrm{NO}_{2}\right)_{2}-\mathrm{O}^{-}$ (Rad2) and $\mathrm{NO}^{\circ}$. The rate-limiting step of the mechanism was the $\mathrm{NO}_{2}-\mathrm{ONO}$ isomerisation through TS1. The Gibbs free energies $\Delta \mathrm{G}_{\mathrm{TS} 1}$ are $60.0 \mathrm{kcal} / \mathrm{mol}$ and $58.1 \mathrm{kcal} / \mathrm{mol}$ for nitro groups a and $\mathbf{b}$, 
respectively, i.e. higher than for the direct $\mathrm{C}-\mathrm{NO}_{2}$ bond dissociation and so non competitive with reaction 1 for the thermal decomposition (with a difference of $36.8 \mathrm{kcal} / \mathrm{mol}$ ).

Elimination of HONO (reaction 3) was computed according to three molecular pathways. First ones issued from interaction of nitro groups $\mathbf{a}$ and $\mathbf{b}$ with hydrogen on the closest carbon (carbon $\mathbf{2}$ ) through transition states TS2a and TS2 $\mathbf{b}$. Then, the concerted breaking of the $\mathrm{C}-\mathrm{H}$ and $\mathrm{C}-\mathrm{N}$ bonds formed, in both cases, nitrous acid (HONO) and 1,1-dinitrobut-1-ene $\left(\mathrm{CH}_{3}-\mathrm{CH}_{2}-\mathrm{CH}=\mathrm{C}\left(\mathrm{NO}_{2}\right)_{2}\right)$, denoted Prod1. Activation Gibbs free energies $\left(\Delta \mathrm{G}_{\mathrm{TS2a}}\right.$ and $\left.\Delta \mathrm{G}_{\mathrm{TS} 2 \mathrm{~b}}\right)$ of $62.3 \mathrm{kcal} / \mathrm{mol}$ and $37.7 \mathrm{kcal} / \mathrm{mol}$ were computed for nitro groups $\mathbf{a}$ and $\mathbf{b}$, respectively. This implies that the reaction on the lateral nitro group is favoured for such mechanism. The third HONO elimination path was obtained from the 1,1,1-trinitrobutane in a cis conformation (SO') which is only $2.5 \mathrm{kcal} / \mathrm{mol}$ higher in $\Delta \mathrm{G}$ than $\mathbf{S O}$. Then, the nitro group $\mathbf{b}$ interacts with hydrogen on the terminal $\mathrm{CH}_{3}$ (i.e. carbon 4 ) through the transition state TS3, leading to the formation of $\mathrm{HONO}$ and of a bi-radical product ${ }^{\circ} \mathrm{CH}_{2}-\left(\mathrm{CH}_{2}\right)_{2}-\mathrm{C}^{*}\left(\mathrm{NO}_{2}\right)_{2}$, denoted Prod2. This reaction path was classified as non competitive with the pathway through TS2 b with an activation energy of $86.0 \mathrm{kcal} / \mathrm{mol}$.

Concerning the elimination of an oxygen from 1,1,1-trinitrobutane (reaction 4), the dissociation of nitrogen-oxygen bonds in nitro groups led to the formation of $\mathrm{CH}_{3}-\left(\mathrm{CH}_{2}\right)_{2}-\mathrm{C}\left(\mathrm{NO}_{2}\right)_{2}-\mathrm{NO}{ }^{\bullet}(\operatorname{Rad} 3)$. This mechanism was computed for both nitro groups $\mathbf{a}$ and $\mathbf{b}$ with respective activation energies $\Delta \mathrm{G}_{\mathrm{Rad} 3}$ of $147.1 \mathrm{kcal} / \mathrm{mol}$ and $147.3 \mathrm{kcal} / \mathrm{mol}$. So, both of them were not competitive.

The last mechanism consisted in the breaking of the carbon-carbon bond that formed trinitromethyl radical $\mathrm{C}^{\circ}\left(\mathrm{NO}_{2}\right)_{3}$ and propyl radical (Rad4). The dissociation Gibbs free energy of this reaction was computed to be $74.7 \mathrm{kcal} / \mathrm{mol}$. This mechanism was not competitive with the reactions involving nitro groups (i.e. reactions 1,2 and 3 ) confirming the specificity of nitro compounds compared to simple alkanes.

Finally, Figure 3 demonstrated that the two most favored reaction paths for the decomposition of 1,1,1-trinitrobutane were the direct breaking of the carbon-nitrogen bond (reaction 1) and the HONO elimination (reaction 3 ) for nitro group b with activation Gibbs free energies of $21.3 \mathrm{kcal} / \mathrm{mol}$ and $37.7 \mathrm{kcal} / \mathrm{mol}$, respectively. All other mechanisms exceeded an activation energy of $58 \mathrm{kcal} / \mathrm{mol}$. This observation is in agreement with previous experimental statements that generally considered these two mechanisms as the most competitive reaction paths for the decomposition of nitroalkanes, as previously mentioned. For this reason, the next steps of this study focused on these two main mechanisms.

It has also to be noticed that in the present case, entropic contribution was of great importance. Indeed, considering Gibbs free energies $(\Delta G)$ allowed the identification of the breaking of the carbonnitrogen bond as the favored pathway whereas HONO elimination would have been considered as competitive based on $\Delta \mathrm{E}$ or $\Delta \mathrm{H}$ results. Indeed, a difference lower than $2 \mathrm{kcal} / \mathrm{mol}$ in the activation energies between the two reactions was calculated (considering $\Delta \mathrm{E}$ or $\Delta \mathrm{H}$ ), as can be seen in table 3 , according to the results issued in previous studies on nitroalkanes ${ }^{22,24}$.

The next step of the study concerned the influence of structural molecular features on the competition between the two main mechanisms highlighted for 1,1,1-trinitrobutane, i.e. the breaking of the $\mathrm{C}-\mathrm{NO}_{2}$ bond and the HONO elimination. 


\section{Influence of the length of the carbon chain}

To investigate the influence of the length of the carbon chain, trinitroalkanes from trinitromethane (1 carbon atom) to trinitrooctane (8 carbon atoms) were considered. The main two decomposition mechanisms highlighted in the previous section (reactions 1 and 3) were computed for these 8 compounds and summarized in table 3 .

Slight increases of activation Gibbs free energies were observed for both reactions for the two smallest molecules but no change was highlighted from trinitropropane (with 3 carbon atoms) for both mechanisms with $\Delta \mathrm{G}_{\text {diss }}=21.1-21.8 \mathrm{kcal} / \mathrm{mol}$ and $\Delta \mathrm{G}_{\mathrm{TS} 2}=37.5-38.0 \mathrm{kcal} / \mathrm{mol}$ (for compounds with 3 to 8 carbon atoms). So, no significant influence of the length of the carbon chain was observed and the carbon-nitrogen bond dissociation remained the main mechanism of decomposition. The $\mathrm{C}-\mathrm{NO}_{2}$ bond dissociation is the main mechanism of decomposition of all tested compounds with $\Delta \mathrm{G}_{\text {diss }}$ ranging from $21.1 \mathrm{kcal} / \mathrm{mol}$ to $26.6 \mathrm{kcal} / \mathrm{mol}$.

Besides, no variation in geometric parameters appeared in the various stationary points when increasing the carbon chain from trinitrobutane to trinitrooctane, as summarized in Supporting Information (Tables S2-S5), with only small deviation for the smallest molecules (trinitromethane and trinitroethane) due to steric effects, in accordance with energetic considerations. Indeed, in the case of trinitromethane, the orientation of the nitro groups is only managed by the steric hindrance between nitro groups. All ONCH dihedral angles (corresponding to the rotation of nitro groups) were calculated to be $42.8^{\circ}$. In the trinitroethane structure, these angles became $43.3^{\circ}$ due to the steric hindrance of $\mathrm{CH}_{3}$ instead of $\mathrm{H}$. Then, from trinitropropane, the configuration of the carbon chain involved a different state of symmetry between nitro groups from a $\mathrm{C} 2 \mathrm{v}$ like configuration to a non symmetric conformation with dihedral angles between $29.0^{\circ}$ and $52.8^{\circ}$. This new conformation is the result of the combined effect of the steric hindrance of the carbon chain and the weak interactions between hydrogen atoms on carbons 2 and 3 and oxygen atoms in nitro groups.

\section{Influence of the presence of double bonds}

Then, the presence of double bonds along the carbon chain was investigated. This corresponds to the case of nitroalkene compounds that were considered as a particular class among C-nitro compounds by Korolev et al. ${ }^{27}$. Three compounds were considered by including double bonds between carbons 2 and 3 (denoted $2=3$ ), between carbons 3 and $4(3=4)$ or both $(2=3=4)$. Reactions 1 and 3 were computed, energetic profiles were reported in table 4 and geometric structures were summarized in Supporting Information (tables S6-S9). Two different features were highlighted as discussed in the following.

For the 3=4 compound, energetic profiles were very similar than those obtained for 1,1,1trinitrobutane with $\Delta G_{\text {diss }}=22.6 \mathrm{kcal} / \mathrm{mol}$ for the breaking of the $\mathrm{C}-\mathrm{N}$ bond and $\Delta \mathrm{G}_{\mathrm{TS2}}=35.4 \mathrm{kcal} / \mathrm{mol}$ for the HONO elimination. For the $\mathbf{2 = 3}$ and $\mathbf{2 = 3 = 4}$ compounds, lower dissociation energies were computed with $\Delta \mathrm{G}_{\text {diss }}=9.2$ and $11.4 \mathrm{kcal} / \mathrm{mol}$, respectively, whereas activation energies of HONO elimination increased at $\Delta \mathrm{G}_{\mathrm{TS} 2}=48.4$ and $44.0 \mathrm{kcal} / \mathrm{mol}$, respectively.

The difference between both cases was due to the closeness of the double bond to the nitro groups. In the structures presenting a $\mathbf{2 = 3}$ double bond (i.e. in $\mathbf{2 = 3}$ and $\mathbf{2 = 3 = 4}$ structures), carbon 2 is in sp2 
hybridation state leading to a different geometric configuration compared to 1,1,1-trinitrobutane and 3=4 compound. Notably, in the Rad1 structures, a weak interaction between the hydrogen on carbon 2 and an oxygen atom of a nitro group led to a planar configuration with NCCC dihedral angle close to $0^{\circ}$ as shown in Figure 5 for the $\mathbf{2 = 3}$ and $\mathbf{2 = 3 = 4}$ structures. However, the angle was about $100^{\circ}$ for the $\mathbf{3}=\mathbf{4}$ structure as for the Rad1 radical for 1,1,1-trinitrobutane.

Finally, the order of preference between reaction $\mathbf{1}$ and $\mathbf{3}$ was not changed between the molecules that do or do not present double bonds between carbons 2 and 3. On the contrary, the activation energy of the most favourable channel ( $\mathrm{C}-\mathrm{H}$ dissociation) was lowered by the presence of these bonds with $\Delta G$ about $10 \mathrm{kcal} / \mathrm{mol}$ (for TNBt and 3=4) compared to more than $20 \mathrm{kcal} / \mathrm{mol}$ for compounds without $\mathbf{2 = 3}$ double bonds (for $\mathbf{2}=\mathbf{3}$ and $\mathbf{2 = 3}=\mathbf{4}$ ). However, present study highlighted no influence of double bonds so far as these bonds are not located in the close surrounding of the nitro groups for these two decomposition channels. This observation is consistent with common statements that considered nitroalkenes as a particular family of compounds ${ }^{26,27}$ so far as nitro groups are close to double bonds. It has to be noticed that in such configuration, further consideration would be necessary to investigate other specific decomposition process ${ }^{26}$.

\section{Influence of substitution on carbon 2, 3 and 4.}

In the following step, substituent effects were investigated. Substitutions on carbons 2, 3 and 4 were considered with six functional groups: methyl $\left(\mathrm{CH}_{3}\right)$, chlorine $(\mathrm{Cl})$, cyano $(\mathrm{CN})$, amino $\left(\mathrm{NH}_{2}\right)$, nitro $\left(\mathrm{NO}_{2}\right)$ and alcohol $(\mathrm{OH})$. This sample of groups was chosen to be representative in the scale of chemical inductive effects as defined by their Taft sigma values $\sigma^{*}$ that ranged from $0.0\left(\right.$ for $\left.\mathrm{CH}_{3}\right)$ to 4.0 (for $\left.\mathrm{NO}_{2}\right)^{52}$. These coefficients were introduced by Taft in the early 1950s on reactions of aliphatic systems $\mathrm{s}^{53-55}$ and more recently used for aliphatic carboxylic acids and alcohols by Zhang et al. ${ }^{56}$ and for aliphatic $\mathrm{CH}_{3} \mathrm{X}$ compounds by Travnikova et al. ${ }^{57}$. The two main decomposition mechanisms highlighted for 1,1,1-trinitrobutane (reactions 1 and 3) were computed for these different compounds and Gibbs free energy profiles were summarized in table 5 . The geometric structures of stationary points are summarized in Supporting Information (Tables S10-S21). An influence of the nature of the substituent was highlighted on carbons 2 and 3. Indeed, for substitution on carbon 2 the dissociation Gibbs free energy of the $\mathrm{C}-\mathrm{N}$ bond varied from $18.2 \mathrm{kcal} / \mathrm{mol}$ for $\mathrm{Cl}$ to $23.4 \mathrm{kcal} / \mathrm{mol}$ for $\mathrm{OH}$ whereas activation energy of the HONO elimination $\Delta \mathrm{G}_{\mathrm{TS} 2}$ changed from $35.5 \mathrm{kcal} / \mathrm{mol}$ for $\mathrm{CN}$ to 39.4 for $\mathrm{OH}$. For substitution on carbon $3, \Delta \mathrm{G}_{\text {diss }}$ ranged from $17.3 \mathrm{kcal} / \mathrm{mol}$ for $\mathrm{Cl}$ to $21.5 \mathrm{kcal} / \mathrm{mol}$ for $\mathrm{OH}$ and $\Delta \mathrm{G}_{\mathrm{TS} 2}$ ranged from 33.7 for $\mathrm{Cl}$ to $37.7 \mathrm{kcal} / \mathrm{mol}$ for $\mathrm{H}$.

It has to be noticed that $\Delta \mathrm{G}_{\text {diss }}$ associated to the breaking of the $\mathrm{C}-\mathrm{N}$ bond decreases when adding a chlorine atom on both carbons 2 and 3 (by -3.1 and $4.0 \mathrm{kcal} / \mathrm{mol}$, respectively). This observation is in agreement with the trend highlighted by Khrapkovskii ${ }^{31}$ for a series of nitromethane derivatives that noticed a decrease of $5.8 \mathrm{kcal} / \mathrm{mol}$ and $11 \mathrm{kcal} / \mathrm{mol}$ from $\mathrm{CH}_{3} \mathrm{NO}_{2}$ to $\mathrm{CH}_{2} \mathrm{ClNO}_{2}$ and $\mathrm{CHCl}_{2} \mathrm{NO}_{2}$, respectively.

Nevertheless, if an influence was exhibited, no linear correlation was directly observed with the Taft sigma values neither for carbon 2 nor for carbon 3 and neither for reaction 1 or for reaction 3 . This can be explained by the fact that the substitutions in carbon 2 and 3 led to steric hindrance issued from the closeness with nitro groups. So, inductive effects as characterized by the $\sigma^{*}$ values revealed not to entirely govern the influence of substituent on carbons 2 and 3 . Indeed, direct interaction 
between the nitro groups and the substituent would also have an effect, in particular on the carbon 2.

To quantify this effect, the different global reactivity descriptors for the different substituted on carbon 2 reactants are given in the table 6 . Charges on $C_{1}$ and $C_{2}$ and the substituent groups were added up, calculated based on the Atomic Polar Tensors (APT) approach ${ }^{58}$. Among the 6 substituents groups, one is electron-donating group $(+\mathrm{I}), \mathrm{CH}_{3}$, and five are electron withdrawing groups $(-\mathrm{I}), \mathrm{NO}_{2}$, $\mathrm{NH}_{2}, \mathrm{OH}, \mathrm{Cl}$ and $\mathrm{CN}$. As expected, the partial charge of $\mathrm{CH}_{3}$ group is slightly more positive than for the hydrogen atom whereas for the other groups the partial charges are negative. Concerning the electron withdrawing groups, the following sequence is found $q(\mathrm{OH})<q(\mathrm{Cl})<q(\mathrm{CN})<q\left(\mathrm{NO}_{2}\right)<q\left(\mathrm{NH}_{2}\right)$ meaning that the stronger group electronegativity in our case was found for $\mathrm{OH}$ group. Looking at the group electronegativity scale obtained by De Proft et al. ${ }^{59}$ at $\mathrm{CISD} / 6-31++\mathrm{G}(\mathrm{d}, \mathrm{p})$ level, the same trend was observed exception given for $\mathrm{OH}$ and $\mathrm{CN}$. However, these two groups belong, with $\mathrm{OCH}_{3}$, $\mathrm{CCH}, \mathrm{SCH}_{3}$ and $\mathrm{SiH}_{3}$, to the "problem" groups as defined by De Proft during their correlation study with other group electronegativity scales. The presence of the substituent groups affects not only the partial charges of the $\beta$ carbon but also the trinitro-substituted carbon with, for this latter, a decrease of $50 \%$ as the substituent groups range from $\mathrm{H}$ to $\mathrm{OH}$. For the others descriptors scales no clear tendency can be extracted.

However, if both mechanisms were affected by the substitution on carbons 2 and 3 , the dissociation of the $\mathrm{C}-\mathrm{N}$ bond remained preferred compared to the HONO elimination, as illustrated in Figure 6 (for carbon 2).

Concerning the substitution on carbon 4, no significant effect was observed neither on the C-N breaking, with $\Delta G_{\text {diss }}$ ranging from $21.1 \mathrm{kcal} / \mathrm{mol}$ for $\mathrm{NH}_{2}$ to $21.6 \mathrm{kcal} / \mathrm{mol}$ for $\mathrm{OH}$, or the $\mathrm{HONO}$ elimination, with $\Delta \mathrm{G}_{\mathrm{TS} 2}$ ranging from $37.5 \mathrm{kcal} / \mathrm{mol}$ for $\mathrm{NH}_{2}$ to $38.2 \mathrm{kcal} / \mathrm{mol}$ for $\mathrm{NO}_{2}$. So, reaction 1 remained the favored mechanism. This is explained by the fact that inductive effects were of only low influence due to the distance between substituents and nitro groups. Moreover, steric hindrance of substituent did not affect the nitro groups.

Finally, it appeared that only substitution on carbons on the close surrounding of nitro groups (from a geometric point of view) led to significant changes in the energetic profiles of the decomposition channels of 1,1,1-trinitrobutane. The inductive effects of substituents, steric hindrance and their possible interaction with nitro groups led to conformational rearrangement. However, whatever the position of the substituents, the competition between the $\mathrm{C}-\mathrm{N}$ bond breaking and the HONO elimination was unchanged and the breaking of $\mathrm{C}-\mathrm{NO}_{2}$ bond remained the favored mechanism.

\section{Case of trinitroalkyl aromatic compounds}

In previous works, nitroaromatic compounds were studied in view of deriving predictive models to evaluate their impact sensitivity based on their molecular structures ${ }^{11}$. In this work, compounds presenting $-\mathrm{R}-\mathrm{C}\left(\mathrm{NO}_{2}\right)_{3}$ fragments were highlighted as a particular class of compounds among aromatic nitro compounds. In previous sections, the $\mathrm{C}-\mathrm{N}$ bond breaking was presented as the primary channel of decomposition of trinitroalkanes with $\Delta G_{\text {diss }}=17.3-23.4 \mathrm{kcal} / \mathrm{mol}$ whereas the loss of nitro groups were calculated to be $\Delta G_{\text {diss }}=47.8-63.0 \mathrm{kcal} / \mathrm{mol}$ in nitrobenzene derivatives (through $\mathrm{C}-\mathrm{N}$ dissociation) ${ }^{17}$ and $\Delta G_{\text {ortho }}=40.2-43.6 \mathrm{kcal} / \mathrm{mol}$ in o-nitrotoluene derivatives (initiated ortho interaction 
between $\mathrm{NO}_{2}$ and $\left.\mathrm{CH}_{3}\right)^{16}$. So, aromatic compounds presenting trinitroalkyl groups may be considered as decomposing in an aliphatic type process by $\mathrm{C}-\mathrm{N}$ bond breaking on the terminal $\mathrm{C}\left(\mathrm{NO}_{2}\right)_{3}$ groups. To validate this statement, two additional molecules were studied, 4-(1,1,1-trinitrobutyl)-nitrobenzene ( $\mathbf{p}-\mathrm{NO}_{2}-\mathrm{Bz}$ ) and 2-(1,1,1-trinitrobutyl)-nitrobenzene (o-NO $\mathbf{N}_{2}-\mathrm{Bz}$ ) (in Figure 7). For these two molecules, the aromatic and aliphatic type mechanisms were computed (see Table 7).

For $\mathbf{p}-\mathrm{NO}_{2}-\mathbf{B z}$, the loss of the nitro groups linked to the aryl ring by dissociation of the $\mathrm{C}-\mathrm{N}$ bond was calculated with $\Delta G_{\text {diss }}=59.0 \mathrm{kcal} / \mathrm{mol}$ whereas similar dissociation for a carbon of the trinitroalkyl fragment was computed with only $\Delta \mathrm{G}_{\text {diss }}=\mathbf{2 1 . 9} \mathrm{kcal} / \mathrm{mol}$. So, $\mathbf{p}-\mathbf{N O}_{2}-\mathbf{B z}$ decomposes in an aliphatic type decomposition process.

In the case of $\mathbf{o}-\mathbf{N O}_{2}-\mathbf{B z}$, an additional aromatic decomposition channel was computed. Similarly to the case of o-nitrotoluene derivatives, the nitro group directly interacts with hydrogen on the first carbon of the alkyl chain in the ortho position. The rate limiting step of this mechanism corresponds to the initial hydrogen transfer from the carbon of the alkyl chain to an oxygen of the nitro group with an activation Gibbs free energy $\Delta G_{\text {ortho }}=41.2 \mathrm{kcal} / \mathrm{mol}$. Otherwise, $\Delta \mathrm{G}_{\text {diss }}$ was calculated at only $21.8 \mathrm{kcal} / \mathrm{mol}$ for the breaking of the $\mathrm{C}-\mathrm{N}$ bond in the $\mathrm{C}\left(\mathrm{NO}_{2}\right)_{3}$ terminal fragment. So, the aliphatictype channel remained favo red in the decomposition of o- $\mathrm{NO}_{2}-\mathbf{B z}$.

Finally, the decomposition process of these two aromatic nitro compounds was initiated on the trinitroalkyl fragment. This confirmed the specificity of such compounds since their decomposition was evidenced to follow the aliphatic behaviour of the trinitroalkyl fragment. Besides, the activation $\Delta \mathrm{Gs}$ of both the C-N bond breaking and the HONO elimination were in the range of the classical trinitroalkanes considered in the previous section. So, such compounds would have to be considered within the same class of compounds in terms of decomposition initiation process.

If the aim of this paper was not to develop QSPR models, the linear correlation between the activation energy of this mechanism, i.e. the dissociation energy of the $\mathrm{C}-\mathrm{NO}_{2}$ bond on the trinitroalkyl fragment, and the impact sensitivities $\left(\log h_{50 \%}\right)$ for such class of compounds gathered in previous works ${ }^{11}$ was considered. But only low correlation between $\Delta G_{\text {diss }}$ and $\operatorname{logh}_{50 \%}$ was observed with 0.58 in $R^{2}$, for the only seven available molecules (as shown in Figure 8). To go further in the finding of a QSPR model, a dedicated study could be realized in the future with a larger dataset.

\section{CONCLUSION}

In this study, the decomposition mechanisms of a series of nitro compounds presenting trinitroethyl fragments were studied by theoretical means based on density functional theory calculations. From the five studied decomposition channels, the breaking of the $\mathrm{C}-\mathrm{N}$ bond (reaction 1) was highlighted as the primary decomposition path with $\Delta \mathrm{G}_{\text {diss }}=21.3 \mathrm{kcal} / \mathrm{mol}$. HONO elimination (reaction 3 ) was the most competitive other channel with $\Delta \mathrm{G}_{\mathrm{Ts} 2}=37.7 \mathrm{kcal} / \mathrm{mol}$.

The influences of various structural parameters on these reaction channels were also studied. Considering the length of the carbon chain, the activation energies of both reactions were slightly lowered from trinitromethane to trinitrooctane. Identically, activation energies were influenced by the substitution of the 1,1,1-trinitrobutane in various sites (in particular on carbon $\mathbf{2}$ and $\mathbf{3}$ ) due to inductive and steric effects of the functional groups. Nevertheless, in both cases, no change in the 
competition between reactions 1 and 3 was highlighted. More influence was observed when considering the presence of double bonds in the carbon chain, explaining the particular character of nitroalkenes, but the $\mathrm{C}-\mathrm{N}$ breaking remained favoured.

From these studies, the breaking of the $\mathrm{C}-\mathrm{N}$ bond was evidenced as the primary channel for the decomposition of such trinitroalkanes. Moreover, it was highlighted, based on the analysis of 4(1,1,1-trinitrobutyl)-nitrobenzene and 2-(1,1,1-trinitrobutyl)-nitrobenzene, that aromatic nitro compounds presenting trinitroalkyl groups are a particular class of aromatic nitro compounds. For these specific compounds, the breaking of the aliphatic $\mathrm{C}-\mathrm{NO}_{2}$ bonds were calculated to be favoured compared to the loss of nitro groups linked to the aromatic cycle. This last observation was in accordance with the identification of this particular family of aromatic nitro compounds in previous QSPR study ${ }^{11}$.

\section{REFERENCES}

1 D. M. Badgujar, M. B. Talawar, S. N. Asthana and P. P. Mahulikar, J. Hazard. Mater., 2008, 151, 289-305.

2 G. Fayet, P. Rotureau, L. Joubert and C. Adamo, Process Saf. Prog., 2010, 29, 359-371.

3 M. J. Kamlet, Sixth Symposium (International) on Detonation, Coronado, CA, 1976.

$4 \quad$ J. A. Morrill and E. F. C. Byrd, J. Mol. Graph. Model., 2008, 27, 349-355.

5 B. M. Rice and J. J. Hare, J. Phys. Chem. A, 2002, 106, 1770-1783.

6 S. R. Saraf, W. J. Rogers and M. S. Mannan, Industrial and Engineering Chemistry Research, 2003, 42, 1341-1346.

7 E. Theerlynck, D. Mathieu and P. Simonetti, Thermochimica Acta, 2005, 426, 123-129.

8 G. A. Melhem and E. S. Shanley, Process Saf. Prog., 1996, 15, 168-172.

9 S. R. Saraf, W. J. Rogers and M. S. Mannan, J. Hazard. Mater., 2003, 98, 15-29.

10 M. H. Keshavarz, J. Hazard. Mater., 2008, 153, 201-206.

11 G. Fayet, P. Rotureau, V. Prana and C. Adamo, Process Saf. Prog., 2012, 31, 291-303.

12 M. H. Keshavarz, J. Hazard. Mater., 2007, 148, 648-652.

13 R. Wang, J. Jiang, Y. Pan, H. Cao and Y. Cui, J. Hazard. Mater., 2009, 166, 155-186.

14 J. C. Dearden, P. Rotureau and G. Fayet, SAR QSAR Environ. Res., 2013, 24, 545-584.

15 G. Fayet, P. Rotureau, L. Joubert and C. Adamo, J. Mol. Model., 2011, 17, 2443-2453.

16 G. Fayet, L. Joubert, P. Rotureau and C. Adamo, J. Phys. Chem. A, 2009, 113, 13621-13627.

17 G. Fayet, L. Joubert, P. Rotureau and C. Adamo, J. Phys. Chem. A, 2008, 112, 4054-4059.

18 A. M. Wodtke, E. J. Hintsa and Y. T. Lee, The Journal of Physical Chemistry, 1986, 90, 35493558.

19 T. B. Brill and K. J. James, Chemical Review, 1993, 93, 2667-2692.

20 T. B. Brill, K. J. James, R. Chawla, G. Nicol, A. Shukla and J. H. Futrell, Journal of Physical Organic Chemistry, 1999, 12, 819-826.

21 A. C. Gonzalez, C. W. Larson, D. F. McMillen and D. M. Golden, Journal of Physical Chemistry, $1985,89,4809-4814$.

22 M. R. Manaa and L. E. Fried, The Journal of Physical Chemistry A, 1998, 102, 9884-9889.

23 E. A. Miroshnichenko, T. S. Kon'kova, Y. O. Inozemtsev, V. P. Vorob'eva and Y. N. Matyushin, Russian Journal of Physical Chemistry B, Focus on Physics, 2008, 2, 595-599.

24 R. V. Tsyshevsky, I. V. Aristov, D. V. Chachkov, A. G. Shamov and G. M. Khrapkovskii, J. Energ. Mater., 2010, 28, 318-337.

25 Q. Wang, D. Ng and M. S. Mannan, Industrial \& Engineering Chemistry Research, 2009, 48, 8745-8751. 
26 G. M. Khrapkovskii, A. G. Shamov, E. V. Nikolaeva and D. V. Chachkov, Russ. Chem. Rev., 2009, 78, 903-943.

27 V. L. Korolev, T. S. Pivina, A. A. Porollo, T. V. Petukhova, A. B. Sheremetev and V. P. Ivshin, Russ. Chem. Rev., 2009, 78, 945-969.

28 G. M. Nazin and G. B. Manelis, Russ. Chem. Rev., 1994, 63, 313-322.

29 T. L. Cottrell, T. E. Graham and T. J. Reid, Transactions of the Faraday Society, 1951, 47, 584590.

30 V. G. Kiselev, V. E. Zarko and N. P. Gritsan, Kinetics and Catalysis, 2006, 47, 351-357.

31 G. M. Khrapkovskii, A. G. Shamov, R. V. Tsyshevsky, D. V. Chachkov, D. L. Egorov and I. V. Aristov, Computational and Theoretical Chemistry, 2012, 985, 80-89.

32 G. M. Khrapkovskii, E. V. Nikolaeva, D. V. Chachkov and A. G. Shamov, Russian Journal of General Chemistry, 2004, 74, 908-920.

33 M. J. S. Dewar, J. P. Ritchie and J. Alster, J Org Chem, 1985, 50, 1031-1036.

34 A. J. Serrano, M. Lorono, T. Cordova and G. Chuchani, Journal of Molecular Structure: THEOCHEM, 2008, 859, 69-72.

35 G. M. Khrapkovskii, A. G. Shamov, R. V. Tsyshevsky, D. V. Chachkov, D. L. Egorov and I. V. Aristov, Computational and Theoretical Chemistry, 2011, 966, 265-271.

36 G. N. Spokes and S. W. Benson, Journal of the American Chemical Society, 1967, 89, 60306035.

37 D. K. Pauler, N. J. Henson and J. D. Kress, Physical Chemistry Chemical Physics, 2007, 9, 5121-

5126.

38 H. A. Taylor and V. V. Vesselovsky, The Journal of Physical Chemistry, 1934, 39, 1095-1102.

39 I. Safarik and O. Strausz, Research on Chemical Intermediates, 1996, 22, 275-314.

40 F. O. Rice and K. F. Herzfeld, Journal of the American Chemical Society, 1934, 56, 284-289.

41 F. O. Rice, Journal of the American Chemical Society, 1931, 53, 1959-1972.

42 G. M. Nazin, G. N. Nechiporenko, D. N. Sokolov, G. B. Manelis and F. I. Dubovitskii, Russian Chemical Bulletin, 1968, 17, 306-312.

43 G. M. Nazin, G. B. Manelis and F. I. Dubovitskii, Russian Chemical Bulletin, 1968, 17, 374-376.

44 C. Adamo and V. Barone, J. Chem., 1999, 110, 6158-6170.

45 M. J. Frisch, G. W. Trucks, H. B. Schlegel, G. E. Scuseria, M. A. Robb, J. R. Cheeseman, G. Scalmani, V. Barone, B. Mennucci, G. A. Petersson, H. Nakatsuji, M. Caricato, X. Li, H. P. Hratchian, A. F. Izmaylov, J. Bloino, G. Zheng, J. L. Sonnenberg, M. Hada, M. Ehara, K. Toyota, R. Fukuda, J. Hasegawa, M. Ishida, T. Nakajima, Y. Honda, O. Kitao, H. Nakai, T. Vreven, J. Montgomery, J. A., J. E. Peralta, F. Ogliaro, M. Bearpark, J. J. Heyd, E. Brothers, K. N. Kudin, V. N. Staroverov, R. Kobayashi, J. Normand, K. Raghavachari, A. Rendell, J. C. Burant, S. S. Iyengar, J. Tomasi, M. Cossi, N. Rega, J. M. Millam, M. Klene, J. E. Knox, J. B. Cross, V. Bakken, C. Adamo, J. Jaramillo, R. Gomperts, R. E. Stratmann, O. Yazyev, A. J. Austin, R. Cammi, C. Pomelli, J. W. Ochterski, R. L. Martin, K. Morokuma, V. G. Zakrzewski, G. A. Voth, P. Salvador, J. J. Dannenberg, S. Dapprich, A. D. Daniels, Ö. Farkas, J. B. Foresman, J. V. Ortiz, J. Cioslowski and D. J. Fox, Gaussian09, Gaussian Inc., Wallington CT, 2009.

46 N. I. Sadova, N. I. Popik and L. V. Vilkov, Journal of Structural Chemistry, 1976, 17, 257-262.

47 H. Schodel, R. Dienelt and H. Bock, Acta Cryst. C, 1994, 50, 1790-1792.

48 M. A. Tafipolsky, I. V. Tokmakov and V. A. Shlyapochnikov, J. Mol. Struct., 1999, 510, 149-156.

49 R. G. Parr and R. G. Pearson, Journal of the American Chemical Society, 1983, 105, 7512-7516.

50 R. G. Parr, R. A. Donnelly, M. Levy and W. E. Palke, The Journal of Chemical Physics, 1978, 68, 3801-3807.

51 R. G. Parr, L. v. Szentpaly and S. Liu, Journal of the American Chemical Society, 1999, 121, 1922-1924.

52 J. A. E. Dean, Lange's Handbook of Chemistry, McGraw-Hill, 1998.

53 R. W. Taft, Journal of the American Chemical Society, 1952, 74, 2729-2732.

54 R. W. Taft, Journal of the American Chemical Society, 1952, 74, 3120-3128. 
55 R. W. Taft, Journal of the American Chemical Society, 1953, 75, 4538-4539.

56 J. Zhang, T. Kleinoder and J. Gasteiger, J. Chem. Inf. Model., 2006, 46, 2256-2266.

57 O. Travnikova, S. Svensson, D. Ceolin, Z. Bao and M. N. Piancastelli, Physical Chemistry Chemical Physics, 2009, 11, 826-833.

58 J. Cioslowski, Journal of the American Chemical Society, 1989, 111, 8333-8336.

59 F. De Proft, W. Langenaeker and P. Geerlings, The Journal of Physical Chemistry, 1993, 97, 1826-1831. 
Table 1 - Bond dissociation energies $(\mathrm{kcal} / \mathrm{mol})$ for trinitroalkanes

\begin{tabular}{lcccc}
\hline & \multicolumn{2}{c}{ experimental } & & calculated \\
\cline { 2 - 3 } & Nazin data $^{a}$ & Lebedev data & & $\Delta \mathrm{E}[\mathrm{PBEO} / 6-31+\mathrm{G}(\mathrm{d}, \mathrm{p})]$ \\
\hline $\mathrm{CH}_{3}-\mathrm{C}\left(\mathrm{NO}_{2}\right)_{3}$ & 94.6 & 95.5 & 96.2 \\
$\mathrm{C}_{2} \mathrm{H}_{5}-\mathrm{C}\left(\mathrm{NO}_{2}\right)_{3}$ & 91.3 & 93.3 & & 92.1 \\
$\mathrm{C}_{4} \mathrm{H}_{9}-\mathrm{C}\left(\mathrm{NO}_{2}\right)_{3}$ & 89.0 & 90.9 & & 92.8 \\
\hline
\end{tabular}

a extracted from ref. 28 
Table 2 - Relative energies $(\Delta E)$, enthalpies $(\Delta \mathrm{H})$ and Gibbs free energies $(\Delta \mathrm{G})$ in $\mathrm{kcal} / \mathrm{mol}$ for the main decomposition channels of 1,1,1-trinitrobutane at PBE0/6-31+G(d,p) level. The decomposition channels are illustrated in Figure 1.

\begin{tabular}{|c|c|c|c|c|c|c|}
\hline & \multicolumn{2}{|c|}{$\Delta \mathrm{E}(\mathrm{kcal} / \mathrm{mol})$} & \multicolumn{2}{|c|}{$\Delta \mathrm{H}(\mathrm{kcal} / \mathrm{mol})$} & \multicolumn{2}{|c|}{$\Delta \mathrm{G}(\mathrm{kcal} / \mathrm{mol})$} \\
\hline & $\mathrm{NO}_{2}(\mathrm{a})$ & $\mathrm{NO}_{2}$ (b) & $\mathrm{NO}_{2}(\mathrm{a})$ & $\mathrm{NO}_{2}$ (b) & $\mathrm{NO}_{2}(\mathrm{a})$ & $\mathrm{NO}_{2}$ (b) \\
\hline So & 0.0 & 0.0 & 0.0 & 0.0 & 0.0 & 0.0 \\
\hline \multicolumn{7}{|l|}{ Reaction 1} \\
\hline $\mathrm{Rad} 1+\mathrm{NO}_{2}$ & 35.4 & 35.4 & 36.0 & 36.0 & 21.3 & 21.3 \\
\hline \multicolumn{7}{|l|}{ Reaction 2} \\
\hline TS1 & 60.0 & 58.5 & 60.0 & 58.5 & 60.0 & 58.1 \\
\hline LM1 & -10.7 & -12.0 & -10.7 & -12.0 & -11.1 & -12.7 \\
\hline $\operatorname{Rad} 2+\mathrm{NO}$ & 24.2 & 23.1 & 24.7 & 23.7 & 12.4 & 10.9 \\
\hline \multicolumn{7}{|l|}{ Reaction 3} \\
\hline TS2 & 62.4 & 38.0 & 62.4 & 38.0 & 62.3 & 37.7 \\
\hline Prod1 + HONO & 6.1 & 6.1 & 6.7 & -6.7 & -6.9 & -6.9 \\
\hline SO' & N.A. & 1.7 & N.A. & 1.7 & N.A. & 2.5 \\
\hline TS3 & N.A. & 83.2 & N.A. & 83.2 & N.A. & 86.0 \\
\hline Prod2 + HONO & N.A. & 0.5 & N.A. & 1.1 & N.A. & -10.7 \\
\hline \multicolumn{7}{|l|}{ Reaction 4} \\
\hline $\operatorname{Rad} 3+O$ & 155.8 & 156.2 & 156.4 & 156.8 & 147.1 & 147.3 \\
\hline \multicolumn{7}{|l|}{ Reaction 5} \\
\hline $\mathrm{Rad} 4+\mathrm{C}^{\circ}\left(\mathrm{NO}_{2}\right)_{3}$ & \multicolumn{2}{|c|}{92.9} & \multicolumn{2}{|c|}{93.5} & \multicolumn{2}{|c|}{74.7} \\
\hline
\end{tabular}


Table 3 - Relative Gibbs Free Energies $(\Delta \mathrm{G})$ in $\mathrm{kcal} / \mathrm{mol}$ for the main decomposition channels of 1,1,1trinitrobutane $\left(n_{c}=4\right)$ and its analogues with different lengths of carbon chain $\left(n_{c}=1-8\right)$ at PBEO/6$31+G(d, p)$ level

\begin{tabular}{|c|c|c|c|c|c|c|c|c|}
\hline $\mathrm{n}_{\mathrm{c}}$ & 1 & 2 & 3 & 4 & 5 & 6 & 7 & 8 \\
\hline so & 0.0 & 0.0 & 0.0 & 0.0 & 0.0 & 0.0 & 0.0 & 0.0 \\
\hline \multicolumn{9}{|l|}{ Reaction 1} \\
\hline $\mathrm{Rad} 1+\mathrm{NO}_{2}$ & 26.6 & 23.5 & 21.8 & 21.3 & 21.5 & 21.5 & 21.2 & 21.1 \\
\hline \multicolumn{9}{|l|}{ Reaction 3} \\
\hline TS2 & N.A. & 40.7 & 38.0 & 37.7 & 37.6 & 37.6 & 37.7 & 37.5 \\
\hline Prod1 + HONO & N.A. & 1.0 & -7.0 & -6.9 & -7.1 & -7.3 & -7.4 & -7.6 \\
\hline
\end{tabular}


Table 4 - Relative Gibbs Free Energies $(\Delta \mathrm{G})$ in $\mathrm{kcal} / \mathrm{mol}$ for the main decomposition channels of 1,1,1trinitrobutane and its analogues presenting double bonds along the carbon chain at PBE0/6$31+G(d, p)$ level

\begin{tabular}{|c|c|c|c|c|}
\hline & 1,1,1-trinitrobutane & $2=3^{a}$ & $3=4^{a}$ & $2=3=4^{a}$ \\
\hline So & 0.0 & 0.0 & 0.0 & 0.0 \\
\hline \multicolumn{5}{|l|}{ Reaction 1} \\
\hline $\mathrm{Rad} 1+\mathrm{NO}_{2}$ & 21.3 & 9.2 & 22.6 & 11.4 \\
\hline \multicolumn{5}{|l|}{ Reaction 3} \\
\hline TS2 & 37.7 & 48.4 & 35.4 & 44.0 \\
\hline Prod1 + HONO & -6.9 & 4.6 & -10.7 & 2.0 \\
\hline
\end{tabular}

${ }^{a} i=j$ : double bonds between carbon atoms labelled $i$ and $j$, respectively 
Table 5 - Relative Gibbs Free Energies $(\Delta \mathrm{G})$ in $\mathrm{kcal} / \mathrm{mol}$ for the main decomposition channels of 1,1,1trinitrobutane and its analogues by substitutions on carbons 2,3 and 4 at PBE0/6-31+G(d,p) level

\begin{tabular}{|c|c|c|c|c|c|c|c|}
\hline on carbon 2 & $\mathrm{H}$ & $\mathrm{CH}_{3}$ & $\mathrm{Cl}$ & $\mathrm{CN}$ & $\mathrm{NH}_{2}$ & $\mathrm{NO}_{2}$ & $\mathrm{OH}$ \\
\hline so & 0.0 & 0.0 & 0.0 & 0.0 & 0.0 & 0.0 & 0.0 \\
\hline \multicolumn{8}{|l|}{ Reaction 1} \\
\hline $\operatorname{Rad} 1+\mathrm{NO}_{2}$ & 21.3 & 19.6 & 18.2 & 20.4 & 22.9 & 18.6 & 23.4 \\
\hline \multicolumn{8}{|l|}{ Reaction 3} \\
\hline TS2 & 37.7 & 38.2 & 38.8 & 35.5 & 38.1 & 37.0 & 39.4 \\
\hline Prod1 + HONO & -6.9 & -12.1 & -9.8 & -9.3 & -26.0 & -5.0 & -23.1 \\
\hline on carbon 3 & $\mathrm{H}$ & $\mathrm{CH}_{3}$ & $\mathrm{Cl}$ & $\mathrm{CN}$ & $\mathrm{NH}_{2}$ & $\mathrm{NO}_{2}$ & $\mathrm{OH}$ \\
\hline SO & 0.0 & 0.0 & 0.0 & 0.0 & 0.0 & 0.0 & 0.0 \\
\hline \multicolumn{8}{|l|}{ Reaction 1} \\
\hline $\mathrm{Rad} 1+\mathrm{NO}_{2}$ & 21.3 & 18.2 & 17.3 & 18.6 & 19.6 & 21.1 & 21.5 \\
\hline \multicolumn{8}{|l|}{ Reaction 3} \\
\hline $\mathrm{TS} 2$ & 37.7 & 34.7 & 33.7 & 35.0 & 36.9 & 36.4 & 36.1 \\
\hline Prod1 + HONO & -6.9 & -10.5 & -9.7 & -8.1 & -6.1 & -5.6 & -6.4 \\
\hline on carbon 4 & $\mathbf{H}$ & $\mathrm{CH}_{3}$ & $\mathrm{Cl}$ & $\mathrm{CN}$ & $\mathrm{NH}_{2}$ & $\mathrm{NO}_{2}$ & $\mathrm{OH}$ \\
\hline SO & 0.0 & 0.0 & 0.0 & 0.0 & 0.0 & 0.0 & 0.0 \\
\hline \multicolumn{8}{|l|}{ Reaction 1} \\
\hline $\mathrm{Rad} 1+\mathrm{NO}_{2}$ & 21.3 & 21.5 & 21.3 & 21.2 & 21.1 & 21.3 & 21.6 \\
\hline \multicolumn{8}{|l|}{ Reaction 3} \\
\hline TS2 & 37.7 & 37.6 & 38.0 & 38.1 & 37.5 & 38.2 & 37.6 \\
\hline Prod $1+$ HONO & -6.9 & -7.1 & -6.4 & -5.9 & -7.1 & -6.2 & -7.1 \\
\hline$\sigma^{* 52}$ & 0.49 & 0.0 & 2.96 & 3.30 & 0.62 & 4.0 & 1.34 \\
\hline
\end{tabular}


Table 6 - Vertical Ionization Potential (I, in eV), Vertical Electron Affinity (A, in eV), Electronegativity $(\chi$, in eV), Chemical Hardness ( $\eta$, in eV), Electrophilicity Index $(\omega$, in eV), charges of the substituent groups ( $q\left(\right.$ group)) and for the carbon atoms $C_{1}$ and $C_{2}\left(q\left(C_{2}\right)\right.$ and $q\left(C_{1}\right)$, respectively).

\begin{tabular}{ccccccccc}
\hline Groups & $I$ & $A$ & $\chi$ & $\eta$ & $\omega$ & $q$ (group) & $q\left(\mathrm{C}_{2}\right)$ & $\mathrm{q}\left(\mathrm{C}_{1}\right)$ \\
\hline $\mathrm{H}$ & 9.6 & 3.4 & 6.5 & 3.1 & 6.8 & 0.04 & -0.04 & 0.28 \\
$\mathrm{CH}_{3}$ & 9.6 & 3.2 & 6.4 & 3.1 & 6.5 & 0.07 & 0 & 0.25 \\
$\mathrm{Cl}$ & 9.3 & 3.5 & 6.4 & 2.9 & 7.2 & -0.24 & 0.27 & 0.18 \\
$\mathrm{CN}$ & 9.9 & 3.7 & 6.8 & 3.1 & 7.5 & -0.18 & 0.08 & 0.22 \\
$\mathrm{NH}_{2}$ & 8.1 & 3.2 & 5.7 & 2.4 & 6.7 & -0.14 & 0.3 & 0.17 \\
$\mathrm{NO}_{2}$ & 9.6 & 3.7 & 6.7 & 2.9 & 7.6 & -0.16 & 0.04 & 0.18 \\
$\mathrm{OH}$ & 9.4 & 3.5 & 6.5 & 2.9 & 7.2 & -0.27 & 0.42 & 0.14 \\
\hline
\end{tabular}


Table 7 - Activation energies in terms of Gibbs free energies $(\Delta G)$ in $\mathrm{kcal} / \mathrm{mol}$ for the main decomposition channels of 4-(1,1,1-trinitrobutyl)-nitrobenzene ( $\left.\mathbf{p}-\mathrm{NO}_{2}-\mathrm{Bz}\right)$ and 2-(1,1,1-trinitrobutyl)nitrobenzene $\left(\mathbf{o}-\mathrm{NO}_{2}-\mathrm{Bz}\right)$ at $\mathrm{PBEO} / 6-31+\mathrm{G}(\mathrm{d}, \mathrm{p})$ level

\begin{tabular}{|c|c|c|}
\hline & $\mathrm{p}-\mathrm{NO}_{2}-\mathrm{Bz}$ & $\mathrm{O}-\mathrm{NO}_{2}-\mathrm{Bz}$ \\
\hline Aliphatic C-N breaking (reaction 1) & 21.9 & 21.8 \\
\hline HONO elimination (reaction $\mathbf{3}$ ) & 38.3 & 38.1 \\
\hline Aromatic C-N breaking & 59.0 & 53.9 \\
\hline C-H ortho attack & N.A. & 41.2 \\
\hline
\end{tabular}


Figure 1 - Decomposition channels of 1,1,1-trinitrobutane

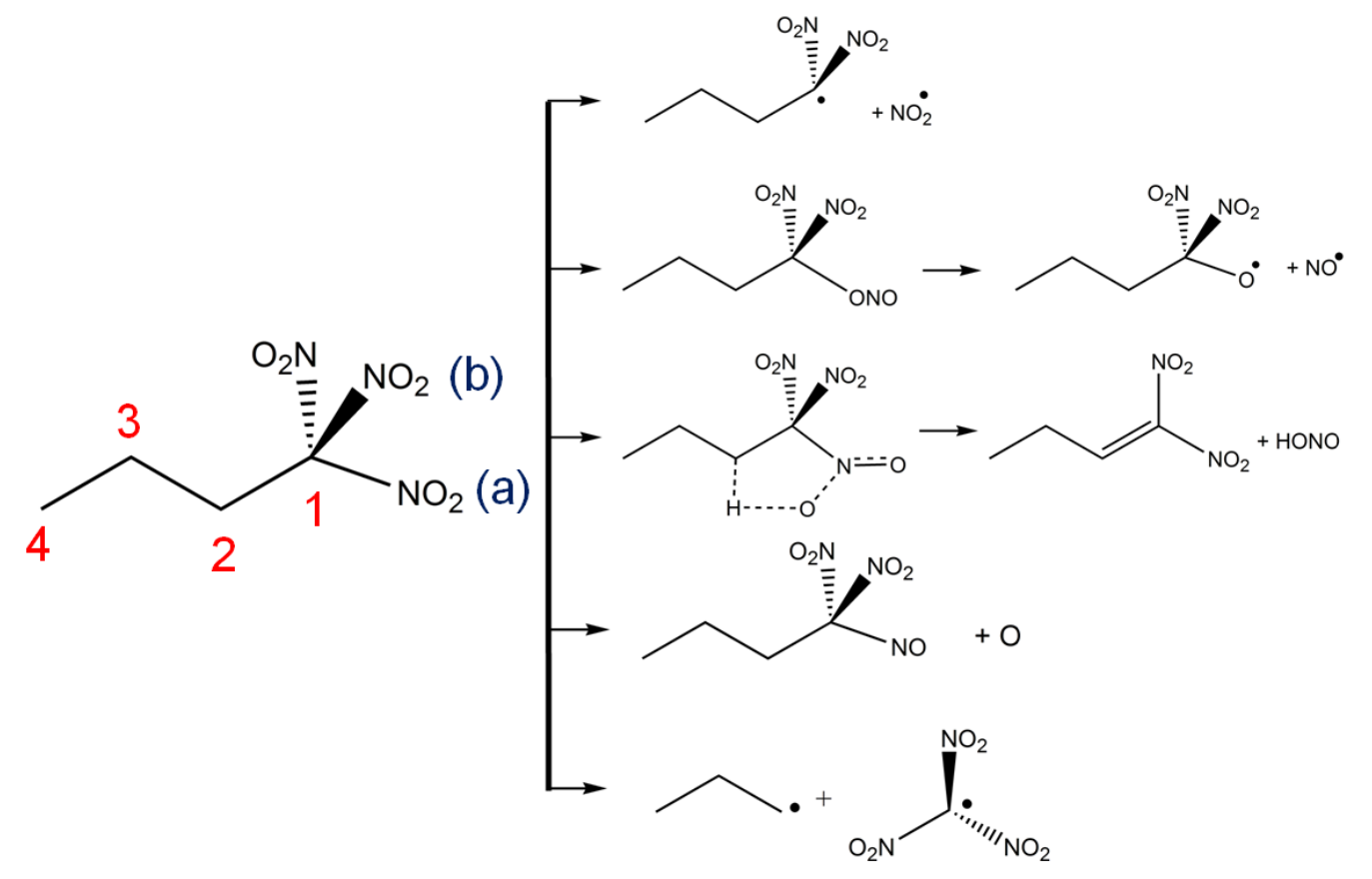


Figure $\mathbf{2}$ - Structure of trinitromethane $\left(C_{2 v}\right.$ symmetry)

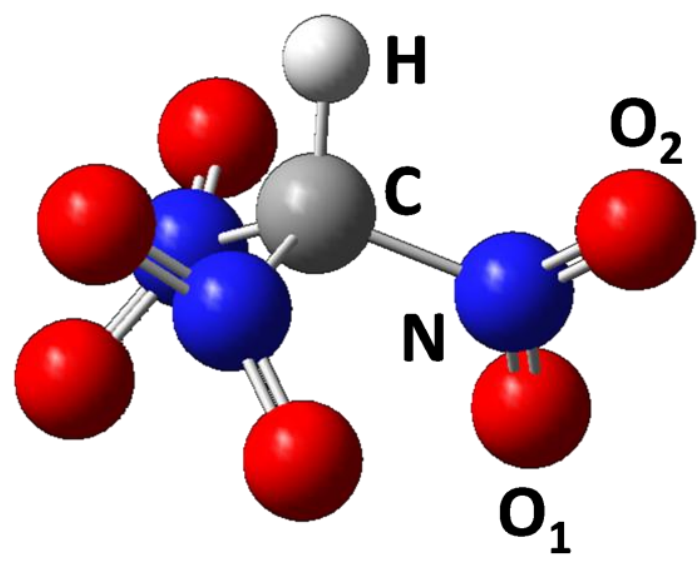


Figure 3 - Relative Gibbs free energy diagram for the main decomposition paths of 1,1,1trinitrobutane calculated at PBEO/6-31+G(d,p) level (see Figure 4 for nomenclature of the different stationary points).

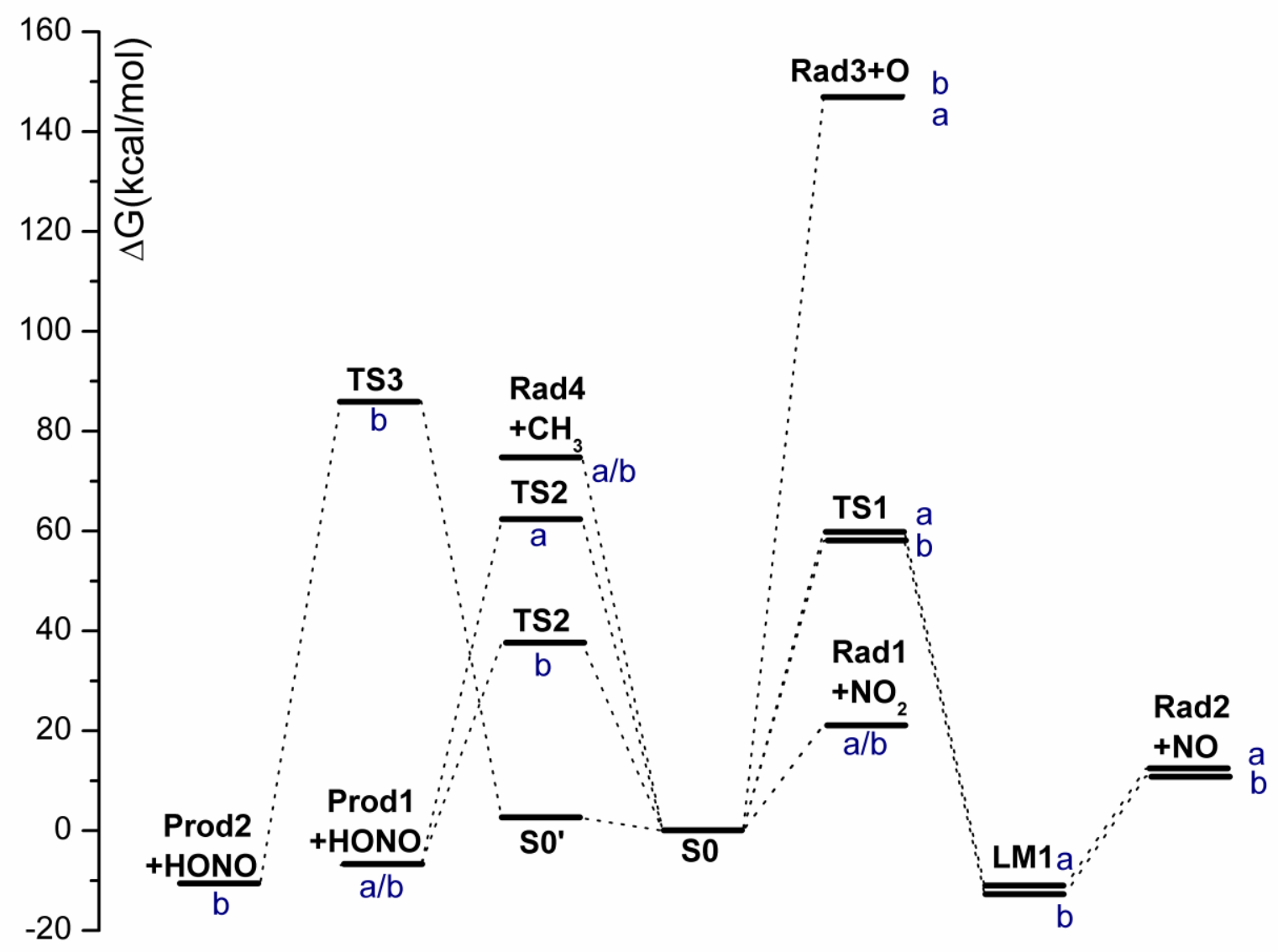


Figure 4 - Structures of the different stationary points (minima and transition states) of the main decomposition channels for 1,1,1-trinitrobutane presented in Figure 3.
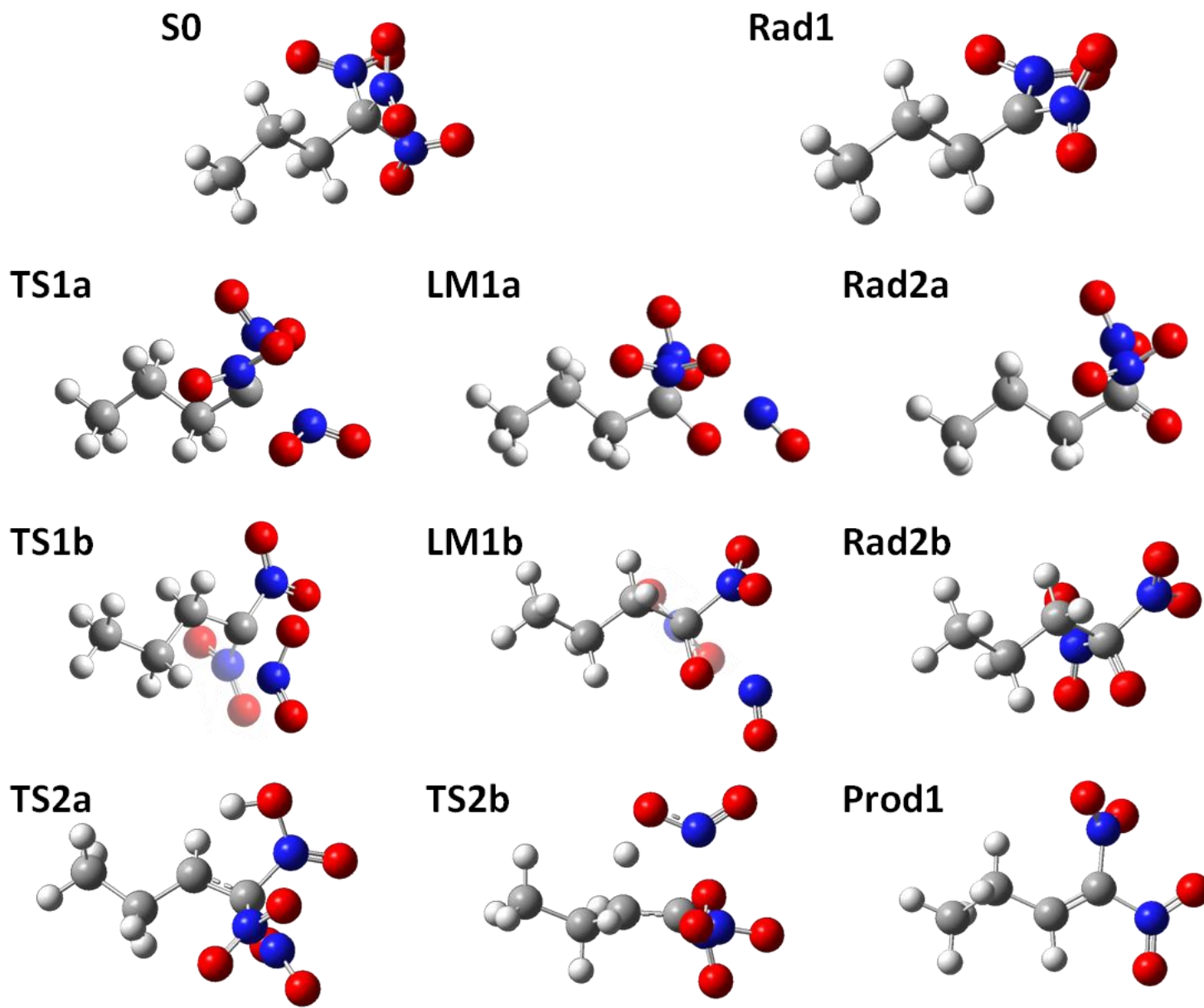

TS2b
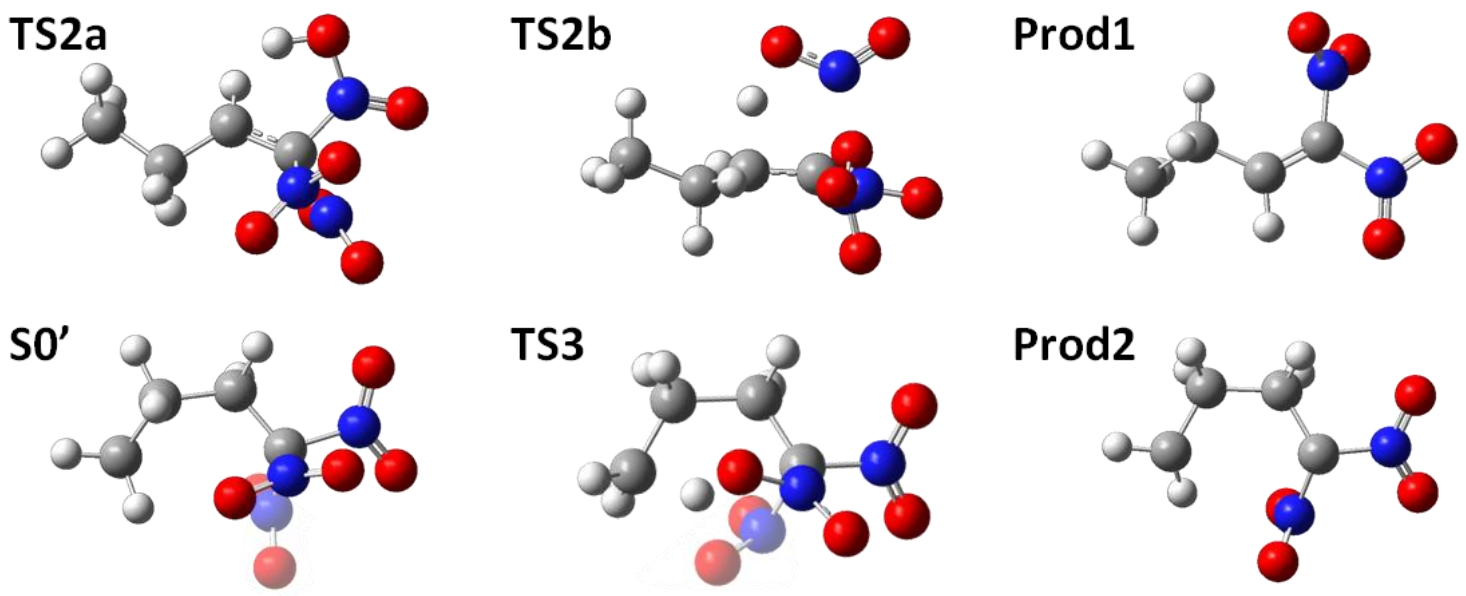

TS3
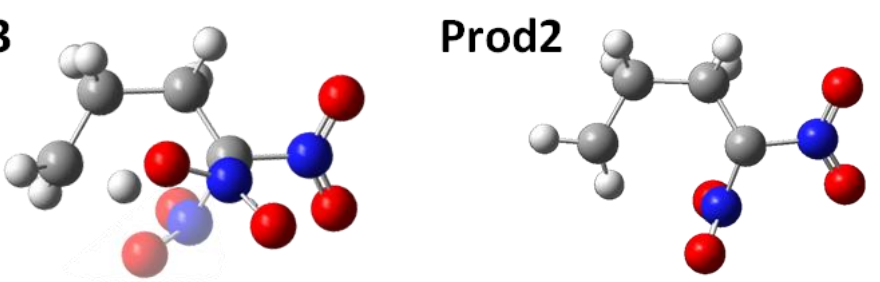

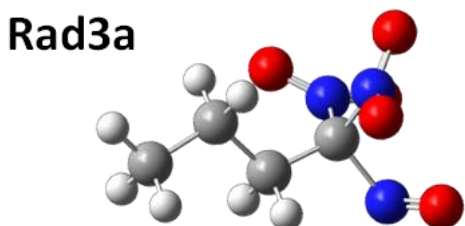

Rad4

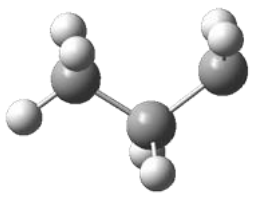

$\operatorname{Rad} 3 b$

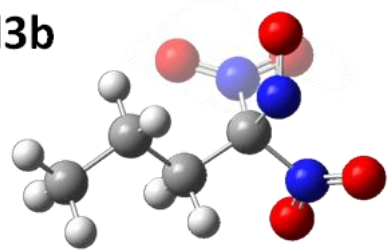

$\mathrm{C}^{\circ}\left(\mathrm{NO}_{2}\right)_{3}$

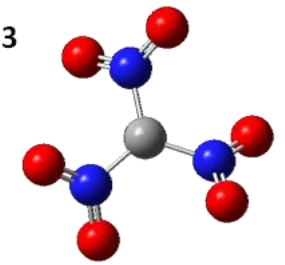


Figure 5 - Influence on the presence of double bonds on the geometric structures of the radicals issued from the $\mathrm{C}-\mathrm{N}$ dissociation $(\operatorname{Rad} \mathbf{1})$

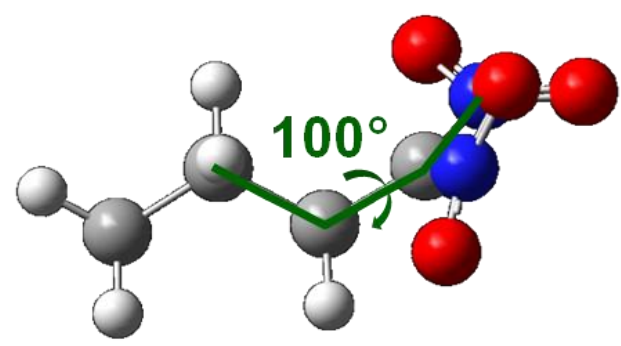

TNBt

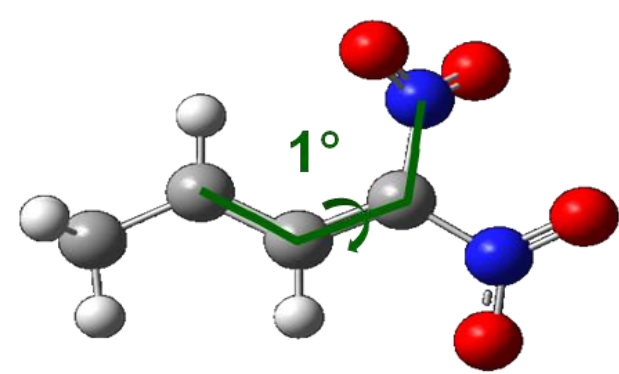

$2=3$

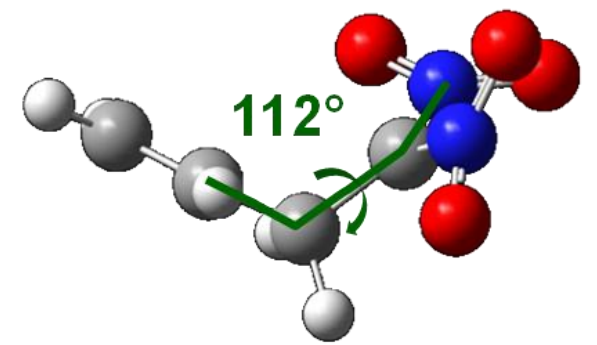

$3=4$

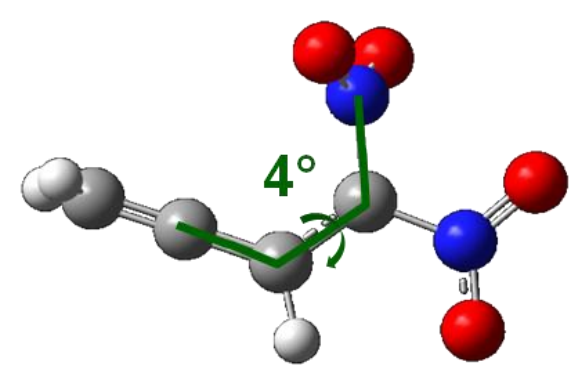

$2=3=4$ 
Figure 6 - Relative Gibbs Free Energies $(\Delta \mathrm{G})$ in $\mathrm{kcal} / \mathrm{mol}$ for the main decomposition channels of 1,1,1-trinitrobutane and its analogues by substitution on carbons 2 at PBE0/6-31+G(d,p)

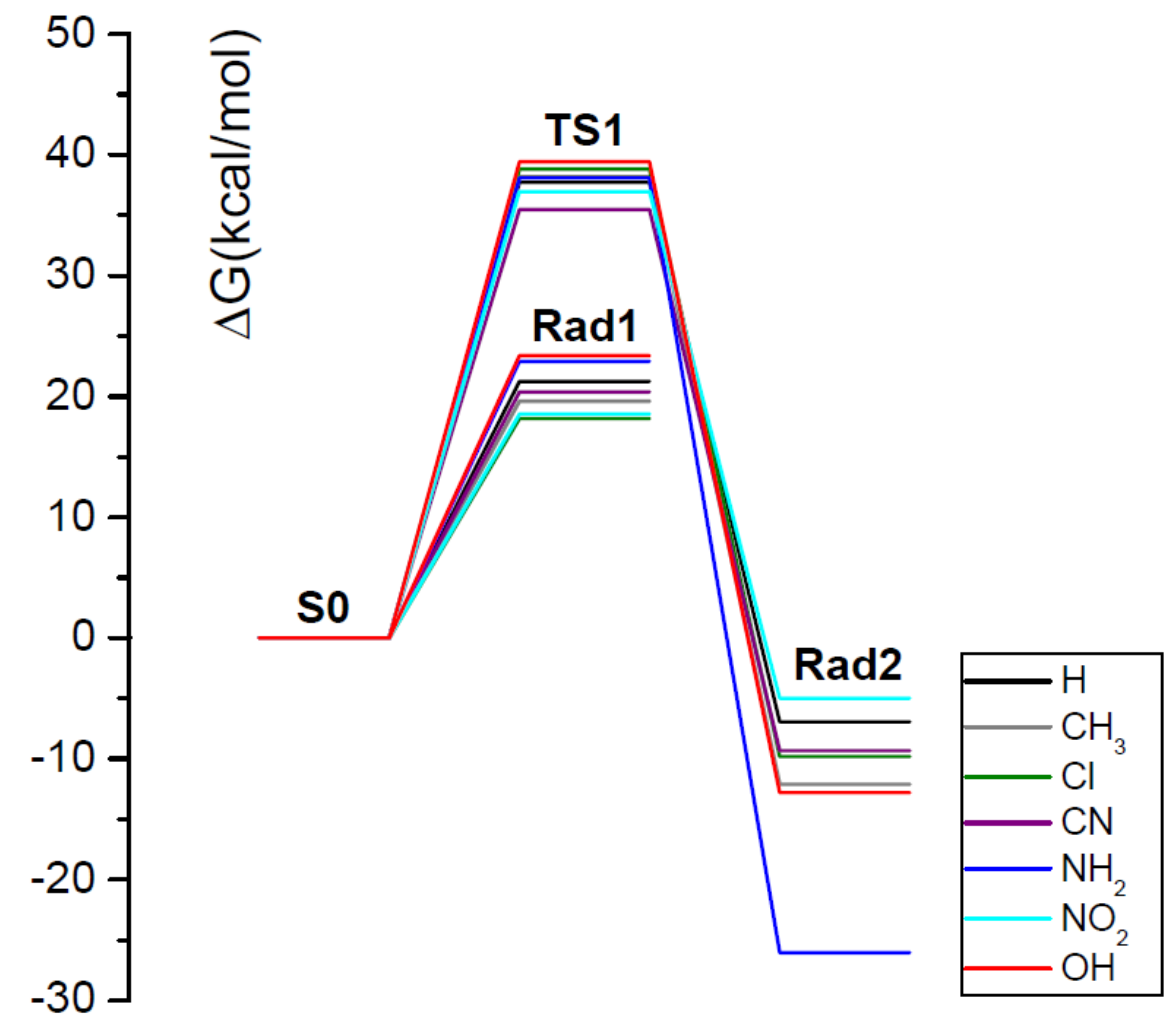


Figure 7 - 4-(1,1,1-trinitrobutyl)-nitrobenzene ( $\left.\mathbf{p}-\mathrm{NO}_{2}-\mathrm{Bz}\right)$ and 2-(1,1,1-trinitrobutyl)-nitrobenzene (o$\left.\mathrm{NO}_{2}-\mathrm{Bz}\right)$

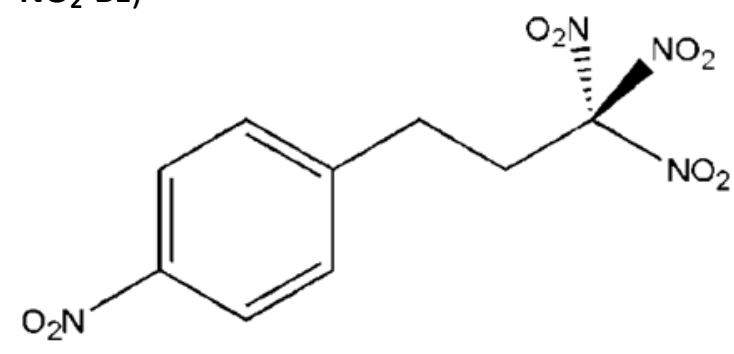

$$
\mathrm{p}-\mathrm{NO}_{2}-\mathrm{Bz}
$$

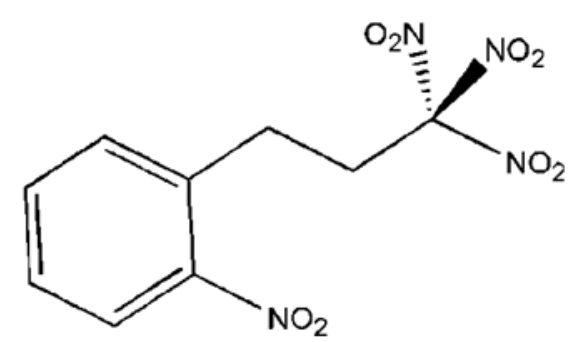

$$
\mathrm{o}-\mathrm{NO}_{2}-\mathrm{Bz}
$$


Figure 8 - Impact sensitivity ( $\log \mathrm{h}_{50 \%}$ ) versus Gibbs free energy of the dissociation of the $\mathrm{C}-\mathrm{NO}_{2}$ bond of the trinitroalkyl fragment.

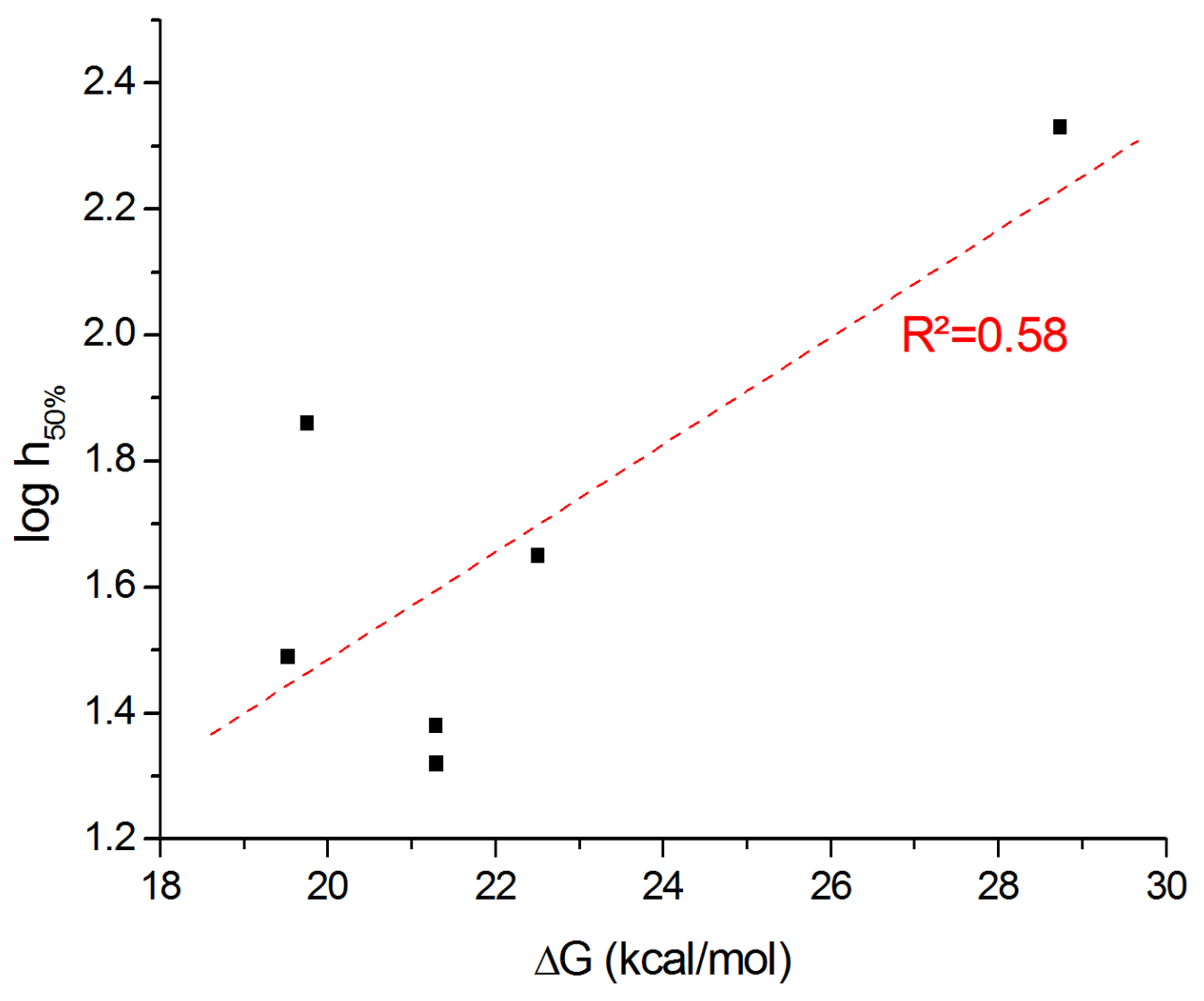

